\title{
Engineered print for zero waste fashion design
}

\author{
F. Nursari \& A. Nabila \\ Telkom University, Bandung, Indonesia
}

\begin{abstract}
Generally, a garment produced using the zero-waste fashion design method focuses on implementing various manipulations of fashion patterns or cutting patterns. The surface design on fabric has not been optimally implemented as a part of the garment because the process of manipulating the clothing pattern is the focus of the design process. The engineered print is one of the surface design techniques used on garments designed with the zero-waste concept. The purpose of this research is to apply the concept of zero waste fashion design to the process of making ready-to-wear clothes in the production process to make it more environmentally friendly and sustainable. The end result is a recommendation on how the basic application of engineered print on the zero-waste garment can lead to a better design process and production.
\end{abstract}

Keywords: Engineered Print, Zero Waste, Fashion Design

\section{INTRODUCTION}

Since 2008, the zero-waste fashion design method, or better known as the abbreviation ZWFD, has been widely studied and practiced by students, academics, and practitioners in the fashion sector who have an interest in the issue of pre-production waste and its effects on the environment. ZWFD itself is a design process that refers to steps in producing clothing with minimum pre-production waste. Pre-production waste itself is waste generated in the process of making clothing, and in the ZWFD process, this waste generally comes from the process of cutting clothing materials.

Generally, clothing that is produced by the zero-waste fashion design method focuses on the implementation of various manipulations of fashion patterns or pattern cutting. Surface or background engineering techniques have not been implemented optimally as one part of fashion is due to the process of manipulating fashion patterns that are the focus of the design process. The engineered print is one of the surface designs utilized in clothing designed with the zero-waste fashion design method. This engineering technique is the development of digital textile printing, which is one of the techniques of digital printing into textile media using printers with a process that is more effective and efficient (Bowles 2012).

In the engineered print technique, fashion patterns can be engineered and arranged precisely with digital software. The motives can be adjusted so that it can produce a seamless visual effect. Garments designed with zero waste fashion design method has a lot of design lines and manipulation of shapes and lines. The application of engineered print techniques can provide a more attractive visual form because of its ability to optimize the motifs used in clothing. The application of engineered print techniques in garments designed with the zero-waste fashion design method has the potential to be implemented for the ready to wear fashion industry. The method is also providing more efficient production time. By applying technology for designing fashion with the zero-waste method, designers can contribute to the fashion industry in order to produce clothing in an environmentally friendly, sustainable, and quality way. Sustainability is a factor that is currently considered by most designers globally due to the many environmental issues that occur due to the impact of the fashion industry waste (Gwilt 2012).

This research begins by reviewing the literature related to the zero-waste fashion design method, the fashion production process, and engineered print technology so that it can be implemented 
precisely in the experimental process. There are two experimental processes in this research, namely, to adopt the manufacturing process in the zero-waste fashion design method and implement engineered print with the help of digital software in generating zero-waste fashion patterns. The result of this research is the evaluation and conclusion of the research and fashion prototype.

\subsection{Zero waste fashion design}

In the fashion industry, two types of waste are produced in the process of producing a garment. First is waste produced by industry, and second is waste produced by consumers. Zero waste fashion design focuses on reducing waste generated during the production process of textile materials and products, also known as pre-consumption waste (Mcquillan 2011). The integration of pattern cutting techniques in the zero-waste concept can optimize the design process. In addition to pattern cutting techniques, there are alternative other techniques that can be applied to produce clothing without pre-consumption waste such as digital printing and draping techniques. The application of the concept of zero waste has been and unwittingly, practiced in traditional clothing in the world (Rissanen \& Mcquillan 2016). The limitation of raw materials and the prolonged fabric production process made people in the past more respectful of material to make clothes so that in every process of making clothes, the material was used entirely without residue.

The practice of zero-waste fashion design methods starts from various forms of traditional clothing. One of the applications of zero-waste fashion design is seen in the form of traditional clothing in Indonesia that utilizes basic geometric shapes in its clothing patterns. Geometric shapes used are generally square, because the fabric material for clothing is made by weaving or felting techniques so that the dimensions of the material produced depend on the size of the loom. Due to the time-consuming and challenging process of making materials, traditional communities will try to optimize the materials available for fashion. Furthermore, because of this tendency, generally, clothing that has passed its lifetime will be reconstructed so that it can extend the wear life of the clothing. The application of the zero-waste fashion design concept seen no change in the optimization of material dimension. However, the resulting clothing designs can be adapted to the tastes, functions, and needs of modern society for fashion at this time. The technique used has evolved and not only focused on the process of utilizing geometric shapes to create clothing patterns but was more explorative with variations in the shape of the design lines and motifs on the material used.

\subsection{Garment production}

There are two different categories in the production process of garment, namely ready-to-wear garments and those according to specific sizes and orders. Some factors that distinguish between the two categories are the stages in the process of clothing production, the process of design considerations, and consideration of the ability to be mass-produced (Onuma 2009).

In the process of producing ready-to-wear clothing or known as ready-to-wear, design considerations that do not only refer to the public who are consumers but need consider several factors such as function, price of production, purchasing power, and sustainability. However, this does not make the ready-to-wear process more time consuming than individual clothing. Due to the dynamic fashion trends, the ready-to-wear fashion industry is more active in producing clothing with different designs. The production process carried out in ready-made clothing can be said to be more modern than clothing for individuals.

Material knowledge is not only limited to the type but can include how the material is following the function of the clothes designed. Making fashion patterns, still through the process of prototyping or making samples of clothing, but at the time the embodiment was carried out on an industrial scale. Furthermore, the process of quality control or inspection of the final product is an important step to ensure product quality.

\subsection{Engineered print}

Engineered printing is one of the engineering techniques that developed along with the development of computer technology and the fashion production process. The engineered printing technique is 
a technique that allows applying motifs to a clothing pattern and printed directly onto a plain cloth so that when the motifs are put together in a seam form, it connects according to the shape of the clothing without being seamless. The use of engineered print is also to add the shape effect of a garment or to accent specific parts of clothing such as cuffs, collars or other specific parts of clothing. One example of using this technique is the work of Alexander McQueen in 2012, where the motif was applied to the pattern to produce a seamless effect.

In using the Engineered Printing application, the conventional method used is scanning flat pattern paper or draping patterns and digital manipulation. As in the work of Hussein Chalayan in 2007 in which Chalayan scanned patterns and then performed digital manipulations to apply motifs to fashion patterns. Digitally compiled patterns applied with motifs using software before finally being printed directly on the surface of plain cloth (Bowles 2012).

\section{METHOD}

Based on the qualitative research method, the experiment carried in this research refers to theories and results from the literature or previous research that supported the topic. Furthermore, conducting the analysis and evaluation process from the experiment results to produce proto- types following the research objectives. The literature study used as a reference for this research is the literature on zero waste fashion design methods, clothing production, and engineered print techniques used as a basis for understanding and limitations in conducting experiments.

The scope of this research is how to apply the zero-waste fashion design method to produce ready to wear clothing. The limitation is narrowed to the application of engineering techniques in the form of engineered print applied to digital patterns of zero-waste garments. The material used is adjusted to the ideal specifications for digital textile printing by utilizing geometric formations in zero waste clothing patterns.

\subsection{Zero waste patterns and engineered print}

The process of obtaining data was carried out by reviewing the literature on various ways of applying zero-waste methods to optimize the cloth dimension with fabric waste below $15 \%$ for a garment. A geometric pattern is one of the basic techniques used in the development of clothes with fabric waste less than $15 \%$. Geometric shapes are also proven to be versatile in flat pattern making with many possibilities of variations depends on the characteristic of the fabric, cutting process, and the position or direction of the pattern on the fabric itself (Nursari \& Djamal 2019). Historically, geometric shapes exist in most traditional garment shape namely kimono, baju kurung, and is the basic shape of ancient Greek and Roman costumes.
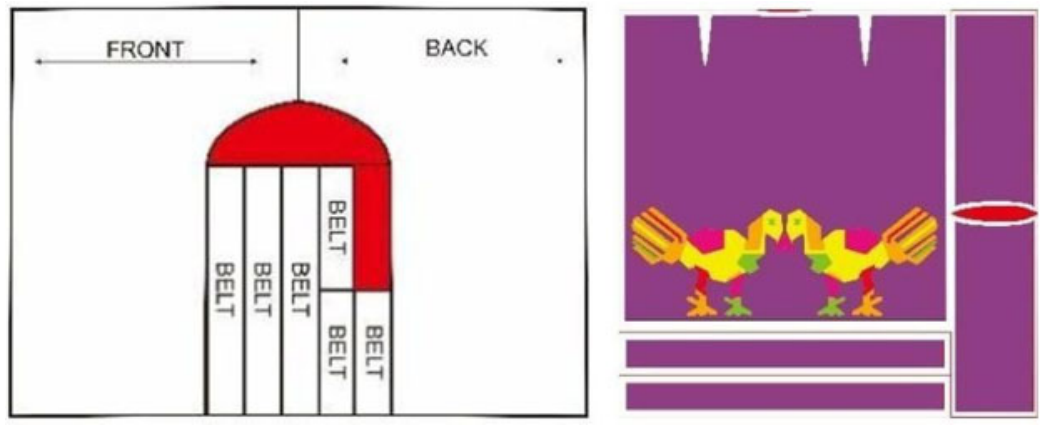

Figure 1. Pattern draft. Source: Nabila, Annisa (2019)

This is the basic geometric pattern plot for a dress with long sleeves. The length is equipped with a ribbon collar and an outer garment in one-shoulder style completed with several belts. The belts 
are part of the design to optimize the fabric width and length and to achieve less than $15 \%$ fabric waste. The overall fabric waste in this design is $3,7 \%$.

Geometric shapes are manipulated in width and length according to the dimension of the fabric used in printing. Corel is used for drafting the patterns instead of paper. The drafting of patterns did not use a specific formula for a basic bodice and sleeve as a foundation pattern. Instead, the designer used the basic measurements of the model to determine the length and width of a few parts of the garment such as sleeve, belt, and dress. The pattern drafting process is done by constructing a rectangular shape with the obtained measurements and adapting the basic details on a foundation pattern such as darts, collar length, and depth. In this process, the designer should have a clear view of how the shape will hold. The main idea is derived from the basic tubular shape of ancient Greek costumes which is well known for its fabric optimization.

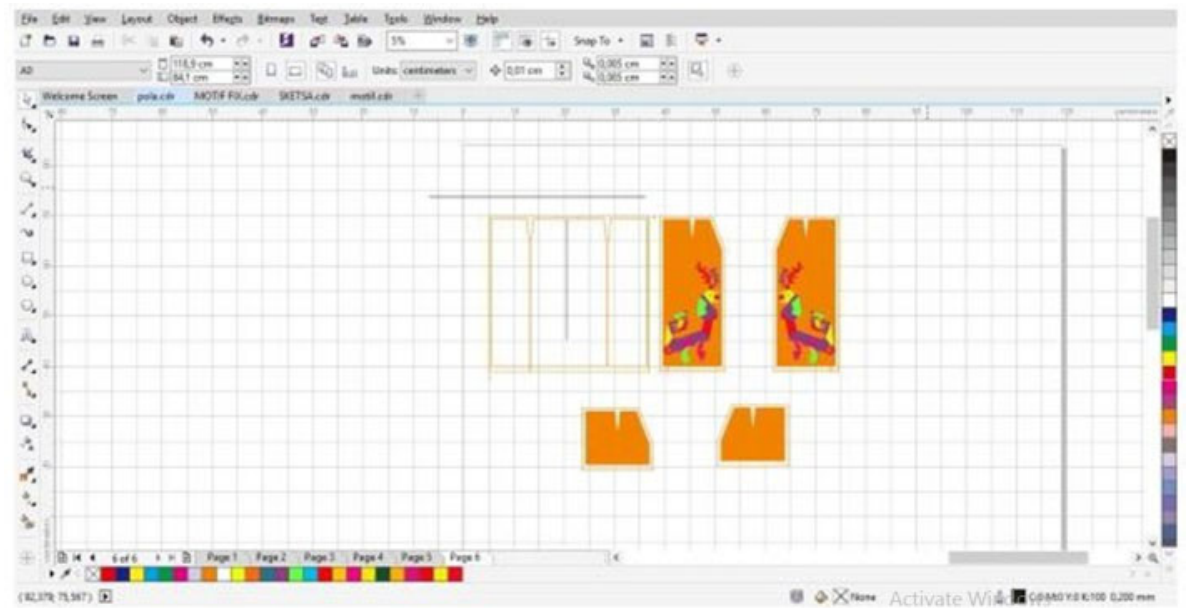

Figure 2. Pattern plot on Corel Draw. Source: Nabila, Annisa (2019)

After the final pattern is constructed in adobe illustrator according to its original measurements, it is manipulated further by deleting unnecessary seams such as side seams and center seams. The elimination of seam will provide a better canvas for the printed motif and ease the assembly process after it is print and cut. When the pattern is set, the last stage is to position the motifs on the garment patterns and adjusting the position accordingly. Seam allowance is then added to the final stage before printing.

\subsection{Producing a garment}

Printing the final garment patterns with the applied motifs is done in the actual fabric dimension due to efficiency and practical reasons in the assembly process. After the printing is done, the fabric is cut out according to its seam allowance and hand-sewn to match the motifs. The hand- sewn garment is inspected for shape and alterations are made during this process. Because of its basic shape, major adjustments are not required for this design. The last stage in production is machine sewing and final inspection of the garment quality.

\section{RESULT}

The result of this research is a dress with long sleeves with a ribbon collar and an outer garment in a one-shoulder style completed with several belts. By using Corel draw as software to draft and manipulate patterns, the designer can effectively produce patterns that are ready to print and sew without wasting paper. 


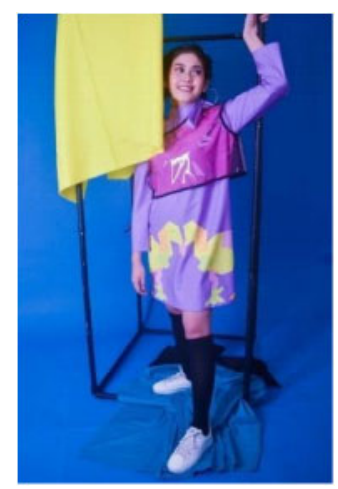

Figure 3. Final design. Source: Nabila, Annisa (2019)

Furthermore, it is possible to reduce fabric waste by $3,7 \%$ by adapting geometric shapes in the design. At the final production stage, the designer used vinyl instead of polyester for the outer garment to achieve a modern and fun look. Although the decision was made in the last stage in the production, it did not have any specific effect on the waste or shape of the garment.

\section{CONCLUSION}

To design a zero-waste fashion collection, having less waste is not only the main concern. The conventional process of drafting garment patterns can lead to the accumulation of pre-consumption waste other than leftover fabrics. To address this issue, the use of digital technology is one of the solutions proposed for designers to create a zero-waste ready-to-wear garment. Industrial pattern making software such as Lectra or Gerber is a few examples where technology is applied to efficiently ease the manufacturing process of a garment. However, each software is expensive for students or independent designers to operate, hence, it is better to send the designs off to be manufactured outside the design studio. This could be difficult if the designer has a specific design process, concept, or other sustainable goals in mind. In this research, such ideas and goals are abled by the simple use of everyday design software such as Corel Draw or Adobe Illustrator. However, the designer should be knowledgeable enough in the foundation of garment construction and software use. This will not only lead to more efficient ways in designing fashion but also create the opportunity for the designer to explore other creative techniques to work with in the future.

\section{REFERENCES}

Bowles, M. (2012). Digital Textile Design Second Edition. London: Lauren King Publishing. ISBN: 9781 780670027

Gwilt, A. (2012). Integrating sustainable strategies in the fashion design process: A conceptual model of the fashion designer in haute couture. School of Architecture + Design College of Design and Social Context. Melbourne: RMIT University Press.

Nabila, Annisa. (2019). Penerapan Metode Zero Waste Fashion Design Deangan Teknik Geometric Cutting Pada Busana Wanita. Bandung(ID): Universitas Telkom.

Nursari, Faradillah, and Fathia H. Djamal. "Implementing Zero Waste Fashion in Apparel Design." 6th Bandung Creative Movement 2019, Bandung, Indonesia, October 2019. Telkom University, 2019, pp. 98-104.

Onuma, S. (2009). Fundamentals of Garment Design. Tokyo: Bunka Publishing Bureau.

Rissanen, T., \& Mcquillan, H. (2016). Zero Waste Fashion Design. London: Bloomsbury. 